T. T. Cloete

T. T. Cloete is emeritus-professor verbonde aan die Noordwes-Universiteit, Potchefstroom. Sy onlangse digbundel is Heilige nuuskierigheid (Tafelberg, 2007).
Resensie-artikel

\section{Tendense in vyf nuwe digbundels}

\section{Review article \\ Tendencies in five new poetry collections}

This article reviews five recent (2008-2009) Afrikaans poetry collections by Antjie Krog, Johann de Lange, Joan Hambidge, Danie Marais and Loftus Marais respectively. Through an integrative discussion the reviewer establishes a number of key tendencies such as these poets' ongoing concern with the nature of poetry or the act of writing, their exploration of intertextual meaning, their parodying or debunking of poetic conventions or their poetical appropriation of the ordinary. Key words: Afrikaans poetry, debunking of poetic conventions, intertextuality, new tendencies.

Digter wordende. 'n Keur vit die gedigte van Antjie Krog.

Antjie Krog. Kaapstad: Human \& Rousseau. 2009. 155 pp. ISBN: 978-0-7981-4926-6.

Die algebra van nood.

Johann de Lange. Kaapstad: Human \& Rousseau. 2009. 128 pp. ISBN: 978-0-7981-5048-4.

Vuurwiel.

Joan Hambidge. Kaapstad: Human \& Rousseau. 2009. 120 pp. ISBN: 978-0-7981-5061-3.

$\mathrm{Al}$ is die maan ' $\mathrm{n}$ misverstand.

Danie Marais. Kaapstad: Tafelberg. 2009. 118 pp. ISBN: 978-0-624-04761-2.

Staan in die algemeen nader aan vensters.

Loftus Marais. Kaapstad: Tafelberg. 2008. 87 pp. ISBN: 978-0-624-04725-4.

Bogenoemde digbundels word nie afsonderlik bespreek nie. Soos versoek deur die redaksie, word tendense aangedui.

Johann de Lange is die digter wat die sterkste aansluit by'n gevestigde tradisie in die Afrikaanse digkuns, wat name insluit soos dié van Ernst van Heerden, Lucas Malan, Ina Rousseau, George Weideman, Stockenström en Sheila Cussons.

Dit is opvallend dat daar by al die digters wat hier bespreek word minder aansluiting is by N. P. van Wyk Louw, D. J.Opperman en Elisabeth Eybers, trouens daar is by sommige van die betrokke digters minder of meer duidelike tekens van ' $n$ kritiese houding teenoor die digterskap van Louw, Opperman en Eybers, al verwys party wel positief na hierdie drie Dertigers se werk. Dit is die amptelike lesers van die literatuur wat die kanon opstel, nie die skrywers self nie, wat hulle weinig steur aan

TYDSKRIF VIR LETTERKUNDE • 47 (1) • 2010 
die kanon of hulle selfs daarteen verset. Daar word in elk geval in die Afrikaanse digkuns nie meer groots opgesette gedigte soos Louw se "Die swart luiperd", "Die hond van God", "Groot Ode" of Opperman se "Brandaansiklus" en "Kroniek van Kristien" geskryf nie. Die enigste uitsondering is Antjie Krog se Lady Anne, maar nou anders gedoen as in die werk van Louw en Opperman: dit word toegepas op die plaaslike historiese en aktuele omstandighede.

Daar is ook nie meer ' $n$ voorliefde vir die geykte vorm soos die sonnet, soos 'n mens dit in die werk van Eybers kry, of vir ander prosodiese skemas nie. Die gedig hoef vir sekere nuwere digters eintlik nie meer konvensionele vers te wees nie, nie meer die "vierkantige" vers nie, om 'n woord van Danie Marais te gebruik, daar is eerder'n voorkeur vir die "vryhandgedig" soos Loftus Marais dit noem ("Aan die fontein in ons flatblock se quad"). Daar is by sekere jongeres nie meer die formeel streng gedissiplineerde gedig soos Van Wyk Louw se "Duif en perd" dit vereis nie. Die opvatting van afgeronde vers en afgeronde gedig het in' $n$ groot mate verdwyn, nie net in Afrikaans nie maar ook in die Europese, Engelse of Amerikaanse poësie. In Krog se gedigte word die versreël soms nie voltooi nie ("depressie"), iets wat ook Gert Vlok Nel in sy debuut baie knap gehanteer het:

ek moet jou. deurstroom van soveel

ligte lieflikheid dat jou ribbes.

dat jy daarvan moet straal.

dat jy genade aan jou boarms.

jy beur verlore. 'n aarde wat.

dis vreeslik om. is vreeslik te sien.

jou so te sien.

"Dimensie kom deur weglating," skryf Krog in "I think I am the first." So lui dit in Hambidge se "4 Driemalig verskyn":

Die gedig sit vol halfryme,

onsekerhede, veral onafhede

Die opvallendste tendens en die een met die hoogste voorkoms by al hierdie digters is die gedig oor die gedig self. 'n Mens kom dit al teen in Krog se debuut: "ek wil vir jou verse skryf" ("Ek wil"). Ons kan dit ook die selfbewuste gedig noem, die gedig wat van homself of haarself praat as "hierdie gedig" (Hambidge, "Cries and Whispers"). "Hierdie vers," "hierdie gedig," frases wat bewus is van die eie-verswees, kom meermale by Hambidge, Krog, Danie Marais en ander voor.

Die gedig oor die gedig is 'n inklusiewe tendens wat baie aspekte van die gedig raak en waaruit baie ander ondergeskikte tendense vertak. 
Wat veral met die tendens van die gedig-oor-die-gedig saamgaan is die relativering, parodiëring of ontluistering van die gedig en van allerlei poëtiese konvensies, veral wat die gedigvorm betref. So'n relativering kom voor in Loftus Marais se "Sewe reaksies op'n seemeeugeraamte," waar sewe moontlikhede getoets word van wat jy sal doen as jy skielik op die strand afkom op'n seemeeugeraamte, met as slot:

7. of jy kan dit net so los

aanstap

en 'n paar woorde daaroor

voor die branders uitkrap

Wallace Stevens het "Thirteen ways of looking at a blackbird" geskryf.

Die gedig as sy eie onderwerp, tema of motief dui op die veranderlikheid van die digkuns, die onophoudelike neiging tot vernuwing daarvan, die veranderlike houding teenoor ouer digters of ouer opvattings van die gedig, reaksies op mededigters, reaksies op opvattings van die literatuur, spesifiek die gedig, byvoorbeeld in Danie Marais se "Die gedweë 'Winternag'":

Jakobus, jy herinner my hoe ons op skool

in die naam van Letterkunde

gedigte se vlerke moes knip;

hoe ons strofes hardhandig moes uitlê

in die klankdigte kamers

van voorgeskrewe simbole in vierkantige lesse ...

Die digter by wie ons die refleksie oor die gedig die veelvuldigste sien, is Joan Hambidge. Iets soos'n reisgedig het, as reisgedig,'n poëtiese titel, "Poësie o poësie," niks van'n reistitel nie. Omgekeerd, waar die titel'n reisgedig in die vooruitsig stel, "In die skadu van Machu Picchu," word die reiservaring gesien as "n argeologie van woorde," en "Macchu Picchu" word as reisgedig "nog'n mislukte sonnet." Hambidge sien talle verskynsels as aspekte van die gedig. Alles is metafoor, woord, taal, vers, en die kontenu skrywende digter is altyd op reis, altyd in die durende proses van'n ontstanende gedig, waarin gepraat word met' $n$ afwesige, gefingeerde hoorder:

In Jaipoer

wag ek die hele dag

op jou soos op 'n metafoor

Dit is ' $n$ prosopopoeia-gedig, soos ' $n$ mens dit veral in die klassieke literatuur kry waar' $n$ versonne of ontbrekende persoon aangespreek word. In Loftus Marais se gedigte word dikwels'n leser aangespreek.

By omtrent al hierdie digters is daar' $n$ neiging om te praat met die leser, met' $n$ suster,'n pa,'n geliefde. 
'n Opvallende verskynsel by'n hele paar van hierdie digters is dat hulle oor die wordende gedig of digterskap skryf. "digter wordende" is die titel van een van Krog se gedigte. In "eerste teken van lewe" (van die ongebore kind), waarin die gedig en die menslike liggaam met mekaar geïdentifiseer word, soos dikwels by Krog, is die proses eintlik nog nie eers aan die gang nie: "' $n$ vers wat vanoggend eindelik begin roer om geskryf te word," "my nog ongeskrewe, maar allergrootste vers." Hambidge se "7 Murder she wrote" is "n durende uitkenningsparade." Terwyl sy skryf, skryf sy (soos 'n mens dit o.a. ook by Krog en Danie Marais teenkom) van "hierdie gedig" ("Cries and Whispers"). In "9 Dood is'n harde ding" is sy besig "om hierdie proses te beskryf." In "10 Droom:moord" duur "hierdie proses" voort. Die opteken van die gedig as proses staan by Hambidge al in die titel van "Die skryfproses as gebreekte sonnet I/II." "Oggend in Jaipoer" eindig met "toe'n vers hieruit ontspruit plots," en "Daardie man wat stap in Jodhpoer" eindig met "so, ja so, is die skryf van hierdie gedig." In "Slangetjies en leertjies" is daar selfs sprake van "hoor ek myself skryf."

In'n groot aantal van Hambidge se gedigte kyk die gedig na die gedig self, omdat ervarings soos reis of die liefde of menslike verhoudings as gedigte beleef word. In verskeie gevalle gaan dit om die feilbaarheid van die gedig; verlies is "die dood van woorde" ("Dood is'n harde ding"), omdat

... wat verlore gaan, nie in rym

of metrum sy beslag kan kry nie

Die gedig is kamer, die kamer is gedig; ander kere is die gedig' $n$ bepaalde reisbestemming, maar dit is nooit dieselfde kamer of bestemming nie, en nooit ' $n$ kamer of bestemming wat duur nie, daarom herskryf Hambidge haar eie gedigte aanhoudend, soos Achterberg.

De Lange se gedigte oor die gedig het'n spontane verwantskap met Hambidge, in sy soektog na die gedig, wat geïdentifiseer word met'n persoon,' $n$ soektog in "falende lig/ na die slot van my gedig." Daardie verwantskap met Hambidge blyk ook uit verse soos "wat hier staan, is geen gedig/veel eerder'n kopreis" ("LSD, Seepunt") of: "Nou sluit ek jou toe in my gedig/ met woorde wat voeg \& 'n klinkende slot" ("Besit"). De Lange plaas'n afdeling "Ars poetica" onder die motto "Words are all I have left of my eyes," van David Dabydeen. By Hambidge lui dit: "Ek is niks/ sonder my woorde." In die eerste gedig van De Lange in die betrokke afdeling ("My woorde is klippe") beskryf hy al die baie moontlikhede van sy taal, soos Van Wyk Louw in sy beiteltjiegedig dit gedoen het. Die gedig hou talle moontlikhede in, die digter dra sy taal "soos'n tweede vel," hy is'n seekat wat kan verkleur of hom kan versteek. Daar is besinnende taalgedigte in hierdie afdeling ("Taal”). Die gedig het iets bedwelmends ("In hierdie nanag"), soos vir Baudelaire.

Ook buite hierdie afdeling is daar by De Lange' $n$ baie bewuste digterskap, onder andere in die afdeling "Memento mori", met as hoogtepunte gedigte oor ander digters: 
Sheila Cussons en Ina Rousseau. Die gedig oor die eie gedig en die gedig oor' $n$ ander digter val in dieselfde kategorie. Van De Lange se gedigte wat die duidelikste uitstaan, is gedigte oor gedigte of digters.

Van die begin af was Antjie Krog skerp bewus van haar digterskap, en dwarsdeur haar oeuvre is daar hierdie selfbewustheid. Sy skryf oor die gedig "terwyl ek skryf", soos sy dit noem in "ode vir'n ander lewe" (ook weer soos by Hambidge en Danie Marais). Krog se bundel wat hier ter sprake is, is ' $n$ keur uit haar werk, en van die eerste gedig af, wat kom uit haar debuutbundel, "Ek wil," karakteriseer sy haar eie vroeëre gedig in sagte vergelykings. In haar bewuste digterskap skryf sy vir (geliefde) mense, wat Hambidge ook doen: sy is in die skryfproses besig om op die gedig te reflekteer: "ek wil vir jou verse skryf;" sy skryf van die ode terwyl sy besig is "om vir jou hierdie ode te skryf" ("ode to a perfect match"); "my poëtiese pluiings/verfokfaai my" ("ons dorp"), "maar dié gedig is vir jou my liefde, /... (die gedig is byna wat jy gedag het") ("1,al die mans wat jy was").

Die woord het vir Krog liggaamlikheid ("onvertaalde teleks VI"), en daarom gaan die gedig maklik oor in die erotiek, soos 'n mens dit ook kry by Hambidge, al sou hierdie twee digters klaarblyklik onafhanklik van mekaar dieselfde tendens openbaar - die identifikasie van teks en erotiek is trouens'n oerliterêre verskynsel ("5.al die mans wat jy was"):

as elke gedig rondom meegee

meteens elke metafoor murg-in verraai

die hele brose bedryf misluk

draai jy na my toe in die bed

Die liggaamlikheid van die gedig, amper soos by Nijhoff, is deur Krog op haar liggaamlikste beskryf in "eerste teken van lewe," oor die ongebore kind:

ek [wou] jou woordeliks vashou...

soos ' $\mathrm{n}$ vers het jy sonder my medewete ontstaan...

' $n$ vers wat vanoggend eindelik begin roer om geskryf te word

... my nog ongeskrewe, maar allergrootste vers.

Hierdie identifikasie van gedig en liggaam of liggaamsfunksie kom ook voor in "vanoggend kon ek" soos by party van die ander onderhawige digters.

Ook nog in Krog se debuutbundel staan die baie bekende gedig "Ma", wat Krog karakteriseer as " $n$ kaalvoet gedig," met herinneringe aan Ingrid Jonker se "Mamma": "mamma is nie meer' $n$ mens nie/ net' $n$ ' $n$," wat op haar beurt weer herinner aan e e cummings se "a salesman is an it..." Dit mag alles vreemde toeval wees, maar so geheimsinnig vervleg is digters en gedigte met mekaar in verskillende lande, tale, tye én liggame! By Hambidge kry ons later "'n gedig sonder fieterjasie" ("2 Tussen-in”).

Die vroeëre "kaalvoet gedig" verskil drasties van Krog se latere verse oor die vers, 
anders as by Hambidge wat onvergenoegd dieselfde idioom probeer deurgrond. In Otters in bronslaai staan daar iets heeltemal anders as 'n kaalvoetgedig: "en ek skryf omdat ek woedend is" ("3.visioen van 'n lessenaar."). In "parool" word die gedig opstand, revolusie en wapen: "poësie moet nuttig wees," "poësie kan rewolusie puur". In hierdie trant is ook no. 2 uit "Gedig oor skuld," , "digter wordende," en "skryfode," waarin die woede weer voorkom:

om te kan skryf moet ek myself binne kom

deur my te buite te gaan

Daardie woede slaan ook uit by Danie Marais.

By Loftus Marais kom ons reeds in die heel eerste gedigte van sy bundel af op die gedig oor die gedig, trouens van die heel eerste versreël af gaan dit om die gedig oor die gedig, dit wat Simon Vestdijk die funksionele gedig genoem het. Marais se gedigte oor die gedig is in verskeie gevalle poëties relativerend, soos ook by Danie Marais. In die tweede gedig, "Papiertjie," waar die halfklaargedig so gevou word dat dit die tafel stabiliseer, word die erns van die gedig gerelativeer. Soos ook by Danie Marais is daar by Loftus Marais verwysings na die spontane gedig, in "Op soek," waar die leser betrek word en direk aangespreek word, wat' $n$ fokusverskuiwing is en waar

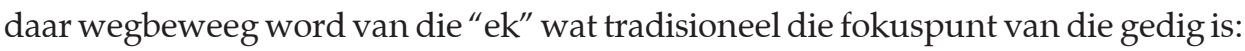
“leser, ek's op soek na'n gedig." Daar is ook so'n soekgedig van P. W. Buys, en dit mag alles weer vreemde toeval wees. Lees ook "Selfportrette op vlekkelose byderwetse oppervlakke," waar al die baie selfportrette van die ek uitloop op'n "onliriese grys," wat daarop neerkom dat met die fokusverskuiwing van die ek af weg ook nie meer geskryf word in wat Ezra Pound melopoeia genoem het nie ("wherein words are charged, over and above their plain meaning, with some music property"), nie meer die "soetsappige soort stront" nie ("Op'n stoep in Oranjezicht") en "al daai ou clichés van waarheid / skoonheid" ("Lightning safety tips..."). Marais gebruik meermaals woorde soos "doodnormaal," "doodgewoon," "alledaags," "spontaan," en die beste voorbeelde van die doodnormale of doodgewone, alledaagse gedig is "Halfagt": "daar word gestort, gebad, toilette word getrek..." ens., en "Oggendlig":

oggendlig deur die retina

maak alles midriatika

'n alledaagse, ooglopende metafisika

Dit is ook nie toevallig nie dat baie verse in Loftus Marais se bundel in en om die huis gevind word. "Die klem moet val op'n meer intieme sfeer," sê Danie Marais in "Saterdagmiddag -'n epiese fragment." In een van die gedigte van Loftus Marais, wat al in sy titel na die gedig self verwys, "'n Gedig vir M," lui die slotreël, wat met'n komma eindig: "enigiets kan in die volgende versreël gebeur," wat daarop neerkom dat dit nie (meer) gaan om die sogenaamde konvensionele afgeronde gedig nie maar om die 
gedig met'n willekeurige oop einde. "die nuwe gedig sal nooit slot hê nie" sê Krog in "'n Gedig oor skuld."

Nie verniet nie verwys Marais na Seamus Heaney ("Gedig vir Seamus Heaney..."), wat self graag gedigte oor die gedig geskryf het, maar in ' $n$ heeltemal ander idioom as Marais. Ook hier die relativering van die gedig: "meneer Heaney, voel: / selfs dié papier was eens'n boom." Miskien is daar in 'n gedig soos hierdie en "Papiertjie" 'n bedekte, dalk onbewustelike korrektiewe toespeling op Opperman se Kalahari's wit papier ("Oud-Digter," óók'n gedig oor die gedig). Nog groter is die waarskynlikheid dat daar in "'n Pleidooi vir vinniger kuns" verwys word na Opperman se "Digter" (weer'n gedig oor die gedig, "die uiteindelike/ reis met die klein skip/ geslote agter glas"), weer met relativering van die gedig:

'n gedig moet dringend kom

soos diaree ...

vat jou bottelskippie

maak dit vol

met petrol

stop'n doek in die nek

vat' $n$ vuurhoutjie

en trek

Onverhole is die relativering van die gedig, tewens die parodieëring van Van Wyk Louw se "Die beiteltjie" in Loftus Marais se "Die digter as rockstar": "ek is die digter in 'n studded leather broek/... ék het nie'n beiteltjie nie/ ek het'n fokken lugdrukboor."

Loftus Marais se gedigte oor die gedig reageer in verskeie gevalle op ander tekste. "Wandeling" is dalk die beste samevatting van sy siening van die digterskap. Die eerste vers, "slaan jou oë af na die teer," kan'n reaksie wees op Ps. 121 ("Ek slaan my oё op na die berge") maar ook op Afrikaanse digters en poësie van die metafisiese. Die gedig van die konkretisme, ondervoetse kom tot die slotsom:

bekyk die dinge binne bereik

die lug is te abstrak

hierlangs, konkreet, ondervoets

lê jou bestemming, jou onderdak

en anyway

staar jy boontoe, meegevoer

sal jy hieronder in 'n paal in moer

'n Umwertung. The times they are a-changin'. Poetry is a destructive force.

Danie Marais het die afwyking van die konvensionele vorm van die gedig die heel verste deurgevoer. By hom word die vers spontane improvisasie. In baie gevalle loop dit by hom uit op die beskrywende gedig, van skynbaar toevallige invalle, 'n 
vrye assosiasie-gedig of impromptu-gedig, in 'n amperse koerant-, brief-, dagboek-, vertelstyl en dialoog.

Eintlik is Danie Marais se byna ongekontroleerde opnoem en beskryf van indrukke' $n$ digterlike ekwivalent van wat ons in die prosa ken as die bewussynstroom, waarmee' $n$ praattaal natuurlikerwys saamgaan, in' $n$ trant wat amper ongewoon is in die Afrikaanse digkuns tot op hede, maar wat tog ook soms by Hambidge voorkom en by Krog. ' $n$ Mens is geneig om 'n term uit die impressionistiese en post-impressionistiese skilderkuns te gebruik en sy gedigte te beskryf as impressies, as pointillisme, pastiche. Of moet' $n$ mens dink aan' $n$ videokamera wat rol en alles spontaan afneem wat in sy gesigsveld kom ("Stilbaai")?:

Dié gedig moet eintlik'n video wees -

'n amateur-video met rukkerige skote

en die klank van die see

wat die dialoog wil-wil versuip.

Dit herinner'n mens aan die fotometafoor by Hambidge, "kiekies, memento's" ("Vergeet-my-nietjie"), asook die raam-metafoor wat by haar voorkom: “... ons raam die oomblik," "Ek raam my herinneringe" ("6 'Gereedskapgesels lei tot omhels'”). Verrassend genoeg kom hierdie raammetafoor ook verskeie kere voor by Loftus Marais in verskeie gedigte ("Die inhoud van hulle huis"):

om die wêreld klein te kry, mak in miniatuur ...

raam vir hulle die wêreld daar buite

In "Selfportrette op vlekkelose byderwetse oppervlakke" lui dit:

ek's geraam in die patryspoorte van wasmasjiene

en nog die beste voorbeeld staan in "Die vroegsomerson as skilder":

die lewe raam homself, hy is een groot galery

In die raam, video- of fotogedig ("kameragedig") is selfs die triviaalste gegewe nie vir Danie Marais onpoëties nie:

Eintlik net om 'n slag weer te praat

asof alles - elke skelm soen en sigaret - belangrik is

en die lewe'n TV-kamera

wat ons soos rock stars agtervolg;

net om weer te kan gesels asof more 'n lang oorsese reis is

wat ons binnekort deeglik sal moet beplan.

Sonder dat die gedig deeglik beplan hoef te word. 'n Goeie voorbeeld is ook "Oornag": 


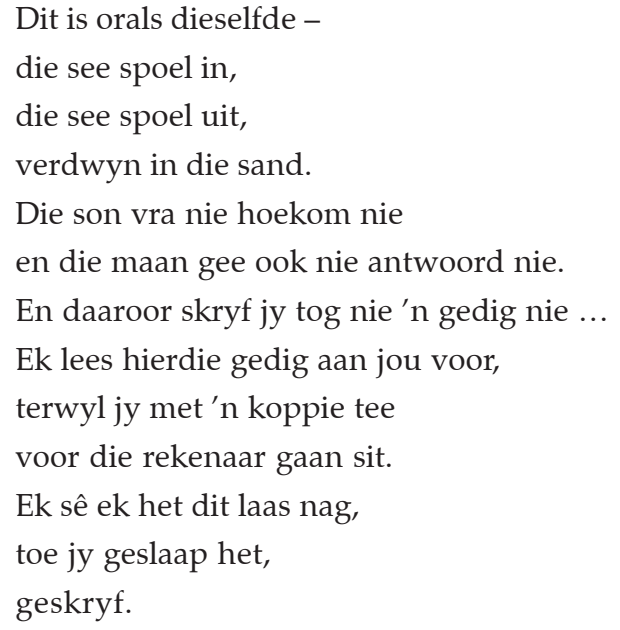

Danie Marais plaas sy gedigte in doodgewone omstandighede en met sy vergelykings ontluister hy bewustelik die poëtiese as 'n aparte fenomeen ("Oukersaand in die Medi-Clinic"):

Dat alles ydel en 'n gejaag na wind is,

is nie juis nuwe idees nie.

Om dit neer te pen op 'n duisend maniere

is sweerlik nie méér sinvol

as om 'n lekkraan reg te maak.

Die skerpste afwysing van die konvensionele opvatting van die gedig staan in "Die gedweë 'Winternag'" wat hierbo aangehaal is.

Danie Marais se spontaan improviserende manier van doen bring mee dat hy minder gedigte skryf wat selfgerig is, tog is hy baie duidelik bewus van hoe en wat en waaroor hy skryf en onder watter omstandighede. Die laaste gedig in sy bundel, “Vir die rekord," is nietemin'n gedig oor die eie gedig, en 'n relativering van die gedig.

By al hierdie digters kom intertekstualitet voor en opdraggedigte aan ander digters, wat intieme verband hou met die gedig wat sy eie onderwerp of motief is. In hierdie opsig is Joan Hambidge weer' $n$ prominente figuur. Sy (en ander) noem onder vele ander Petrarca, Eybers, Wallace Stevens, Neruda. Loftus Marais verwys ook na Wallace Stevens, na Heaney en ander. De Lange verwys dikwels na ander digters: Van Wyk Louw, Ina Rousseau, Cussons, William Carlos Williams, Eybers, Aucamp, Hambidge, Kerkorrel, Ernst van Heerden, Ingrid Jonker, Rupert Brooke, Achterberg ...

Die subtekste in die gevalle van intertekstualiteit is nie altyd ander gedigte nie maar ook die ander kunste, films, skilderye, kreatiewe figure wat buite-literêr kreatief is, soos byvoorbeeld Ingmar Bergman, Liv Ullmann (Hambidge). Meestal is dit weer 
eens die korter gedig wat berus op 'n subteks, en meestal word die subteks in die gedig genoem, nie soos in die geval van "Die swart luiperd", wat'n betreklik lang gedig is wat op' $n$ besonder lang ander teks (Goethe se Faust) berus en wat op so'n subtiele manier gedoen is dat dit die Afrikaanse kritiek tot dusver ontgaan het.

Vanselfsprekend is daar by sommige van hierdie digters, uit die aard van hulle bewuste digterskap, ook'n skerp taal- of woordbewustheid, veral by Hambidge, De Lange en Krog. Bewuste digterskap en taalbewustheid sluit die een die ander in. De Lange dra sy taal "soos'n tweede vel" ("Die digter as inkvis"). Die hele afdeling "Ars Poetica" is vol taal- en woordbewustheid, selfs al in die titels van party gedigte. De Lange haal Schopenhauer aan: "The word of man is the most durable of all material." "My woorde is klippe," is die titel van een van De Lange se gedigte. In "Besit" lui dit: Ek sluit jou toe in my gedig met woorde wat voeg...

Krog se "ek speel die spel met woorde" ("vanoggend kon ek") is maar 'n enkele voorbeeld onder vele. Haar "skryfode" is vol taal- en woordbewustheid:

woorde wil jou nie los nie

woorde kry jou nie gehou nie

En by Hambidge lui dit ("Ek is niks"):

Ek is niks

sonder my woorde

nie

Wat die poëtiese woordeskat betref, het die jongere Afrikaanse poësie baie meer pront geword as voorheen. Opperman en Boerneef het, van agterna gesien, skugter daarmee begin. Wat ons miskien die beste kan beskryf as liggaamstaal of lyfskryf, kom volop voor, dan ook onverbloemde erotiese taal, en koprotaal. Nie meer die "suiwer woorde" waarvoor Van Wyk Louw gevra het in sy "Opdrag" in Die halwe kring met sy "hoër, kouer paaie" nie, nie meer die presieuse taal van'n W. E. G. Louw nie maar'n pront taalgebruik, wat ons nie alleen in die onderhawige bundels kry nie (met name by Krog en Hambidge, ook by Loftus Marais) maar ook by Ronelda Kamfer in haar debuut, wat reeds in Tydskrif vir Letterkunde 46 (1) bespreek is.

Daarnaas kom die gewone praattaal of geselstaal volop voor by omtrent al hierdie digters, en dan mengtaal, wat deur party taalkundiges Engrikaans genoem word. Maar Adam Small en Snyders was die meeste van hulle almal ver vooruit wat dit betref. Hoe dan ook, nie meer sonder meer "standaard-afrikaans" nie (Loftus Marais: "Oorgeklank"). Inteendeel, party van hierdie digters, met name Krog, de-standaardiseer die Afrikaanse digterlike woordeskat. 
Die invloed van die elektronika en komper (internet, sms, kuberruim, google, selfoon, video, printer, tv, film, kamera, ens.) slaan oral uit, veral by Hambidge.

Die ontluistering van die poëtikale raak nie net die taal nie maar ook die onderwerp van die gedig, soos ' $n$ mens dit vind in die lesbiese figuur by Hambidge, die gay-figuur by De Lange, die erotiek (Hambidge, Krog, De Lange) of selfs dwelms, soos in De Lange se "Van Gogh met naald," waar die soek na ontsnapping uitloop op'n Van Goghgesig (vgl. Afdeling II, “Bedrieglike Paradyse").

Krog het dit samevattend gestel ("wintergedigte 2, dinge natuurlik"):

dinge natuurlik waaroor' $n$ mens nooit 'n gedig sou skryf nie

dring in die nuwe territory poetic temas binne

soos om tampon en pad te ruil te pie in toilette

By sommige van hierdie digters word die digterlike daarbenewens tog ook gesoek in die onderwerp wat vanself vatbaar vir die poëtiese is, byvoorbeeld medelye met die lydendes.

Dit kom ook daarop neer dat daar meer gekyk word na die nabye. Vergelyk Loftus Marais se "Wandeling" wat hierbo aangehaal is. Dit gaan in baie van hierdie gedigte nie meer om die "hoër, kouer paaie" nie. In De Lange se "Ostranenie" lui dit:

maar ek kwel my nie oor tydlose dinge

want God het ook vir fibonacci uitgedink

Op sy eie manier weet De Lange hoe om van dit wat "lelik" is'n mooi gedig te maak.

In "Die maraboe" gee hy erkennig aan Ina Rousseau:

die marabou is jammerlik

lelik

Van Keetmanshoop

tot Katmandoe

strek die ryk van die marabou.

In "Ommesientjie" lees mens

Wat skedelig mooi is, of geil, of onguur

word 'n tydlose oogwink jou tweede natuur.

Buiten hierdie tendense is daar vanselfsprekend nog baie ander in die Afrikaanse digkuns, wat baie verskillend hiervan is, en daar is nog baie ander digters wat vandag aan die orde van die digterlike dag is en die karakter van die Afrikaanse digkuns in belangrike mate bepaal: Louis Esterhuizen, Carina Stander, Johan Myburg, Ronelda Kamfer, Trienke Laurie, Zandra Bezuidenhout, Henning Pieterse, om slegs enkeles te noem. 